\title{
Development and Validation of Formulae for the Estimation of Solids-not- Fat and Total Solids Content in Cow and Buffalo Milk
}

\author{
V. M. Arjuna ${ }^{1}$, N. Laxmana Naik², Akshaykumar ${ }^{3 *}$, B. K. Ramesh ${ }^{3}$, \\ Shivanand $^{2}$, Sharanabasava ${ }^{2}$ and K. N. Krishna ${ }^{4}$ \\ ${ }^{1}$ Hatsun Agro Products, Chennai, India \\ ${ }^{2}$ National Dairy Research Institute, SRS, Bengaluru, India \\ ${ }^{3}$ ICAR-Krishi Vigyan Kendra, Bidar, India \\ ${ }^{4}$ Dharwad Co operative Milk Union, Dharwad, India \\ *Corresponding author
}

\section{A B S T R A C T}

\section{Keywords}

Lactometer, Fat,

Solids not fat and

Corrected

Lactometer reading

Article Info

Accepted:

17 June 2020

Available Online:

10 July 2020

Milk testing for quality assurance is an essential component of any milk processing industry. Pricing of milk is mainly based on the percentage level of fat and solids-not-fat (SNF) contents. Different types of lactometers and different formulae are in use for estimating SNF and TS percentage. Gravimetric method is the standard and accurate method for estimation of SNF. However, this method is time consuming and demands a better analytical skill. Therefore, this study was undertaken to develop a suitable formulae and validation of the same. In this study total 339 milk samples (154 individual and pooled milk samples from Deoni and HF cow from Institute Livestock Research Centre, 135 individual and pooled buffalo milk samples from Yelahanka and Chikkaballapura, 25 commercial samples from Experimental dairy Plant and 25 Market samples) were collected and analyzed. Twenty-two lactometers (ISI and Zeal), 25 milk butyrometer, 8 milk pipettes and 9 thermometers were calibrated and used in the study. Correlation between fat and SNF for cow and buffalo milk was established by using SPSS-16.0 version statistical tool. Regression equation for prediction of coefficient (Fat and CLR in the formula) and constant was used. In, ISI, S1, New $27^{\circ} \mathrm{C}, \mathrm{S} 2 \mathrm{~S} 3$ and New $29^{\circ} \mathrm{C}$ formula $74.07,75.77,80.24,9.33,0$ and 77.33 total percentage of samples are within $0.2 \%$ error in SNF for buffalo milk and in case of cow milk 88.98, 73.72, 91.52, 35.48, 5.64 and 91.93 total percentage of samples were within $0.2 \%$ error in SNF. Based on these observations 4 formulae were developed, for buffalo milk F1=0.25CLR $+0.25 \mathrm{Fat}+0.38$ at $27^{\circ} \mathrm{C}$ and $\mathrm{F} 2=$ $0.25 \mathrm{CLR}+0.25 \mathrm{Fat}+0.57$ at $29^{\circ} \mathrm{C}$. For cow milk, F3=0.25CLR $+0.25 \mathrm{Fat}+0.39$ at $27^{\circ} \mathrm{C}$ and $\mathrm{F} 4=0.25 \mathrm{CLR}+0.25 \mathrm{Fat}+0.56$ at $29^{\circ} \mathrm{C}$. Validation result for these formulae shows that $80.24,77.33,91.52$ and 91.93 percentage of samples were within the acceptable range. The developed formula helps in estimating the SNF and TS contents in milk nearer to the gravimetric value.

\section{Introduction}

Milk testing for quality assurance is an essential component of any milk processing industry. Chemical quality control and assurance tests are designed to ensure that the milk and dairy products meet accepted 
standards for compositional parameters and purity as well as levels of different components. Raw milk of good quality is the basis for the production of high quality dairy products. Milk payment strategies differ across the world as the markets, product portfolios, consumer and farmer preferences change. Pricing policy is very important for any organized enterprises. It should comply with the standards laid by the law regulating agencies. The initial good quality milk is allocated high price. Pricing in many countries depends mainly on the quantity of milk and fat and SNF\% (Sandhu, S. S. 2003). In most of the countries, the following chemical quality characteristics have been set for raw milk reception; (a) fat percentage, (b) total solids (TS) or solids-not-fat (SNF) percentage (c) protein content and (d) the temperature $\left({ }^{\circ} \mathrm{C}\right)$ of received milk. Based upon the chemical analysis results, raw milk is graded. In milk, fat and Snf are variable, in India pricing of milk is based on quantity and quality i.e. fat and Snf content of milk. To ensure the quality of milk, the minimum standards for milk have been fixed by the legal authorities "Food Safety Standard Authority of India (FSSAI).The Richmond's formula using specific gravity lactometer has been widely used in our country for calculating the solids-not-fat in cows and buffaloes milk. By using this formula wide variations in the results with gravimetric method have been reported by different workers. A slight error in the estimation of fat and SNF, especially when the milk is handled in large quantities in a dairy plant, can result in big discrepancies in the balance sheets and recovery amounts (Bector and Sharma, 1980). Usually fat will be estimated by Gerber, Mojonnier and instrumental methods. Most commonly used method for fat estimation is Gerber, but Mojonnier method is the reference (standard) method for fat estimation. The determined level of SNF in milk varies somewhat with the method of estimation. Gravimetric method is the standard and accurate method for estimation for SNF. However, this method is time consuming and demands a better analytical skill. Lactometric methods are rapid and simple. Now a day's different states using different formulae and different lactometers for the estimation of Solids not fat and total solids in milk but most of the formulae underestimates Snf by $>0.2 \%$. Therefore, the present study is being undertaken to bring $\% \mathrm{SNF}$ estimated by formula method maximum near to gravimetric method by developing a possible uniform formula for determination of SNF and TS contents in both cow milk and Buffalo milk.

\section{Materials and Methods}

Fresh individual cow milk samples from Holstein Friesian (HF), Deoni and pooled milk samples from $\mathrm{HF}$ and Deoni cow was collected from the Livestock Research Centre (LRC) of Southern Regional Station (SRS) of ICAR-National Dairy Research Institute, Adugodi, Bengaluru. Buffalo milk samples were collected from two places; Yelahanka, Bengaluru and Vaddahalli, Chikkaballapura District, Dairy co-operative society. From Yelahanka Bengaluru. Commercial raw milk samples were collected in the morning from Experimental Dairy Plant of SRS, ICARNDRI, Adugodi, Bengaluru. Each $500 \mathrm{ml}$ of milk was collected and analyzed for required parameters. Five different types of milk packets were collected from Nandini outlet Adugodi, Bengaluru. Each of 10 samples were collected (cow, standardized, toned, double toned, full cream milk) and these were used for validation study. Cream was used for the spiking studies in order to check the effect of level of fat on lactometer reading. Skim milk powder (SMP)used to increase the SNF content of milk to assess the effect of increase in SNF on lactometer reading. 
Depending on the temperature of measurement of density of milk different types of lactometers are used. In this study, two temperatures, one at $27^{\circ} \mathrm{C}$ for which ISI lactometer was used and another at $29^{\circ} \mathrm{C}$ for which Zeal lactometer was used. Butyrometer was used to check the fat percentage by Gerber method. Milk pipette of $10.75 \pm 0.03$ $\mathrm{ml}$ volume was used for the determination of fat in milk. Thermometer was used for temperature assessment during lactometer reading checking.

Calibration of lactometer (IS: 9585: 1980), butyrometer (IS: 1233 Part 1, 1970), milk pipette (IS: 1223, 2001), thermometer (IS: 1223 -1970) were done by ISI procedure.

Number of each samples used for this study was individual buffalo $(\mathrm{n}=135)$, individual Deoni $(n=48)$, individual cross breed $(n=45)$, pooled Deoni $(n=31)$, pooled cross breed $(n=30)$, commercial raw $(n=25)$, market milk $(n=25)$. Totally 339 samples were used for this study.

Four formulae were used for comparison with standard method i.e. gravimetric method based on that a regression equation was developed and compared with standard method for estimation of solids-not-fat.

ISI, $\% \mathrm{SNF}=0.25 \mathrm{CLR}+0.25 \mathrm{Fat}+0.44$

State $1, \% \mathrm{SNF}=0.25 \mathrm{CLR}+0.25 \mathrm{Fat}+0.35$

State $2, \% \mathrm{SNF}=0.25 \mathrm{CLR}+0.20 \mathrm{Fat}+0.50$

State 3, \% SNF=0.25CLR+0.20Fat+0.36

Where, State 1=Karnataka, State $2=$ Kerala, State 3=Tamil Nadu

\section{Results and Discussion}

Before analysis all the glassware were calibrated according to standard procedures. Raw milk samples were collected from different sources, analyzed for fat Snf content. Fat is estimated by Gerber method and Snf content is estimated by both formula and gravimetric method. Results from gravimetric value compared with existing formulae deviation from standard value of the formulae results were noted, according to that an regression equation was developed by using spss 16.0 version and results of the developed formula were compared and spiking studies were also studied.

\section{Buffalo milk}

Fresh raw buffalo milk samples were collected and analyzed for $\%$ fat and \%Snf. Varrichio et al., (2007) reported the fact that the fat content has an average value of $8.3 \%$ but can also reach up to $15 \%$ under normal conditions Frequency distribution table I shows total percentage of samples which are in the different SNF (\%) range. ISI formula shows $3.70 \%$ of samples were underestimating (negative side) by $>0.2 \%$ SNF and $22.22 \%$ of samples were overestimating (positive side) by $>0.2 \% \mathrm{SNF}$, in State 1 formula $19.75 \%$ of samples are underestimating (negative side) $>0.2 \% \mathrm{SNF}$ and $2.46 \%$ of samples are overestimating (positive side) by $>0.2 \%$ SNF. State 2 formula shows that $90.66 \%$ of samples are underestimating, in case of state 3 formula $100 \%$ of samples showing underestimation. Mean difference ( $\%$ error) of the formulae results of ISI, S1, S2 and S3 are $0.06 \pm 0.16$, $0.03 \pm 0.16,-0.41 \pm 0.17$ and $-0.55 \pm 0.17$. For these 4 formulae underestimation is in the order of S3>S2>S1>ISI and overestimation is in the order of ISI $>$ S1.Above results can be seen from fig 1 .

\section{Cow milk}

Fresh raw cow milk (individual Deoni, Individual cross breed, pooled Deoni, pooled cross breed and commercial raw) were 
collected and analyzed for \%fat and \%Snf. Based on observation that the deviation from standard value, new formula has been developed, it can be seen from the table II shows the fallowing observations that at $27^{\circ} \mathrm{C}$ average gravimetric, ISI, S1 and New formula SNF values were $9.13 \pm 0.35,9.25 \pm 0.34$, $9.20 \pm 0.34$ and $9.14 \pm 0.34$. At $29^{\circ} \mathrm{C}$ average gravimetric, S2, S3 and New formula SNF values were $9.11 \pm 0.36,8.85 \pm 0.33$, $8.71 \pm 0.33$ and $9.12 \pm 0.35$. Mean difference $(\%$ error) of the formulae results of ISI, S1, New 27, S2, S3 and New 29 are $0.12 \pm 0.15$, -
$0.07 \pm 0.15,0.01 \pm 0.15,-0.26 \pm 0.14,-0.40 \pm$ 0.14 and $0.01 \pm 0.14$. By observing the fig 2 we can conclude that in, ISI, S1, New 27, S2 S3 and New 29 formula 88.98, 73.72, 91.52, $35.48,5.64$ and 91.93 total percentage of samples are within $0.2 \%$ error in SNF. Therefore, from this data we can say that by using new formula, $\%$ of errors was minimized. At 27 in case of new formula $91.52 \%$ and at $2991.93 \%$ samples are in the acceptable range (within $0.2 \%$ error).Above results can be seen from fig 2 .

Table.1 Frequency distribution of \% Error in SNF of buffalo milk samples

\begin{tabular}{|c|c|c|c|c|c|c|}
\hline \multicolumn{7}{|c|}{ Frequency $n=81$ (for $27^{\circ} \mathrm{C}$ samples), $n=75$ (for $29^{\circ} \mathrm{C}$ samples) } \\
\hline $\begin{array}{c}\% \text { SNF } \\
\text { difference }\end{array}$ & ISI & S1 & N 27 & S2 & $\mathbf{S 3}$ & $\mathbf{N} 29$ \\
\hline-0.91 to -1.0 & & & & & 2 & \\
\hline-0.81 to -0.90 & & & & & 2 & \\
\hline-0.71 to -0.80 & & & & 4 & 12 & \\
\hline-0.61 to -0.70 & & & & 6 & $15(20)$ & \\
\hline-0.51 to -0.60 & & & & 15 & 13 & \\
\hline-0.41 to -0.50 & & & & 16 & 13 & \\
\hline-0.31 to -0.40 & & 3 & 2 & 10 & 14 & 3 \\
\hline-0.21 to -0.30 & 3 & 13 & 7 & $17(22.66)$ & 4 & 7 \\
\hline-0.11 to -0.20 & 13 & 14 & 14 & 4 & & 13 \\
\hline-0.01 to -0.10 & 15 & $17(20.98)$ & 18 & 3 & & 14 \\
\hline 0 & 4 & 3 & 2 & & & 2 \\
\hline 0.01 to 0.10 & 15 & 13 & 12 & & & 10 \\
\hline 0.11 to 0.20 & 12 & $17(20.98)$ & $19(23.45)$ & & & $19(25.33)$ \\
\hline 0.21 to 0.30 & $16(19.75)$ & & 5 & & & 4 \\
\hline 0.31 to 0.40 & 1 & 2 & 2 & & & 3 \\
\hline 0.41 to 0.50 & 1 & & & & & \\
\hline
\end{tabular}


Table.2 Frequency distribution of \% error in SNF of Combined cow milk samples

\begin{tabular}{|c|c|c|c|c|c|c|}
\hline \multicolumn{7}{|c|}{ Frequency $n=118\left(\right.$ for $27^{\circ} \mathrm{C}$ samples), $n=124\left(\right.$ for $29^{\circ} \mathrm{C}$ samples) } \\
\hline $\begin{array}{c}\% \mathrm{SNF} \\
\text { difference }\end{array}$ & ISI & S1 & N 27 & S2 & S3 & N 29 \\
\hline $\begin{array}{c}-0.81 \text { to }- \\
0.90\end{array}$ & & & & & 1 & \\
\hline $\begin{array}{c}-0.71 \text { to }- \\
0.80\end{array}$ & & & & 1 & 4 & \\
\hline $\begin{array}{c}-0.61 \text { to }- \\
0.70\end{array}$ & & & & 2 & 3 & \\
\hline $\begin{array}{c}-0.51 \text { to }- \\
0.60\end{array}$ & & 1 & 1 & 5 & 18 & \\
\hline $\begin{array}{c}-0.41 \text { to }- \\
0.50\end{array}$ & 1 & & & 10 & 32 & 1 \\
\hline $\begin{array}{c}-0.31 \text { to }- \\
0.40\end{array}$ & & 14 & 4 & 10 & $36(29.03)$ & 2 \\
\hline $\begin{array}{c}-0.21 \text { to }- \\
0.30\end{array}$ & 12 & 16 & 5 & $40(32.25)$ & 23 & 7 \\
\hline $\begin{array}{c}-0.11 \text { to - } \\
0.20\end{array}$ & 7 & 17 & 14 & 24 & 2 & 8 \\
\hline $\begin{array}{c}-0.01 \text { to - } \\
0.10\end{array}$ & 16 & 29 & 26 & 18 & 5 & 22 \\
\hline 0 & 3 & 6 & 4 & 1 & & 12 \\
\hline 0.01 to 0.10 & $33(27.96)$ & $32(27.11)$ & $34(28.81))$ & 1 & & 25 \\
\hline 0.11 to 0.20 & 30 & 11 & 21 & & & $36(29.03)$ \\
\hline 0.21 to 0.30 & 10 & 7 & 9 & & & 8 \\
\hline 0.31 to 0.40 & 6 & 2 & 1 & & & 3 \\
\hline
\end{tabular}

Table.3 Summary of \% SNF analysis of milk samples $\left(27^{\circ} \mathrm{C}\right)$

\begin{tabular}{|c|c|c|c|c|c|}
\hline $\begin{array}{c}\text { Source of } \\
\text { samples }\end{array}$ & \% Fat & \%SNF g & \%SNF ISI & \%SNF S1 & \%SNF N \\
\hline Buffalo & $6.70 \pm 0.64$ & $10.12 \pm 0.30$ & $10.18 \pm 0.30$ & $10.09 \pm 0.30$ & $10.12 \pm 0.30$ \\
\hline Individual Deoni & $4.97 \pm 0.83$ & $9.39 \pm 0.28 \pm$ & $9.48 \pm 0.28$ & $9.39 \pm 0.28$ & $9.43 \pm 0.28$ \\
\hline Individual H.F. & $4.38 \pm 0.98$ & $9.06 \pm 0.25$ & $9.11 \pm 0.21$ & $9.02 \pm 0.21$ & $9.06 \pm 0.21$ \\
\hline Pooled Deoni & $4.23 \pm 0.43$ & $9.32 \pm 0.2$. & $9.37 \pm 0.15$ & $9.28 \pm 0.15$ & $9.32 \pm 0.15$ \\
\hline Pooled H.F. & $4.15 \pm 0.41$ & $8.97 \pm 0.24$ & $9.01 \pm 0.28$ & $8.92 \pm 0.28$ & $8.96 \pm 0.28$ \\
\hline Commercial raw & $3.64 \pm 0.50$ & $8.74 \pm 0.26$ & $8.77 \pm 0.25$ & $8.68 \pm 0.25$ & $8.72 \pm 0.25$ \\
\hline milk & & & & & \\
\hline
\end{tabular}


Table.4 Summary of \%SNF analysis of milk samples $\left(29^{\circ} \mathrm{C}\right)$

\begin{tabular}{|c|c|c|c|c|c|}
\hline $\begin{array}{c}\text { Source of } \\
\text { samples }\end{array}$ & \%Fat & \%SNF g & \%SNF ISI & \%SNF S1 & \%SNF N \\
\hline Buffalo & $6.76 \pm 0.69$ & $10.14 \pm 0.25$ & $9.73 \pm 0.27$ & $9.59 \pm 0.27$ & $10.14 \pm 0.27$ \\
\hline $\begin{array}{c}\text { Individual } \\
\text { Deoni }\end{array}$ & $4.97 \pm 0.83$ & $9.39 \pm 0.32$ & $9.13 \pm 0.26$ & $8.99 \pm 0.26$ & $9.44 \pm 0.27$ \\
\hline $\begin{array}{c}\text { Individual } \\
\text { H.F. }\end{array}$ & $4.27 \pm 0.96$ & $9.03 \pm 0.27$ & $8.75 \pm 0.22$ & $8.61 \pm 0.22$ & $9.03 \pm 0.23$ \\
\hline $\begin{array}{c}\text { Pooled } \\
\text { Deoni }\end{array}$ & $4.27 \pm 0.43$ & $9.34 \pm 0.20$ & $9.04 \pm 0.19$ & $8.90 \pm 0.19$ & $9.31 \pm 0.19$ \\
\hline Pooled H.F. & $4.11 \pm 0.42$ & $8.91 \pm 0.24$ & $8.69 \pm 0.23$ & $8.55 \pm 0.23$ & $8.95 \pm 0.24$ \\
\hline Commercial & $3.65 \pm 0.53$ & $8.70 \pm 0.27$ & $8.45 \pm 0.26$ & $8.31 \pm 0.26$ & $8.69 \pm 0.27$ \\
\hline raw milk & & & & & \\
\hline
\end{tabular}

Table.5 Refined equation for calculating \% SNF and \% TS in buffalo and cow milk

\begin{tabular}{|l|l|l|}
\hline Type of milk & \multicolumn{1}{|c|}{ At $27^{\circ} \mathbf{C}$} & \multicolumn{1}{c|}{ At $2{ }^{\circ} \mathbf{C}$} \\
\hline \multirow{2}{*}{ Buffalo milk } & $\% \mathrm{SNF}=0.25 \mathrm{CLR}+0.25 \mathrm{Fat}+0.38$ & \%SNF=0.25CLR+0.25Fat+0.57 \\
\cline { 2 - 3 } & $\% \mathrm{TS}=0.25 \mathrm{CLR}+1.25 \mathrm{Fat}+0.38$ & $\% \mathrm{TS}=0.25 \mathrm{CLR}+1.25 \mathrm{Fat}+0.57$ \\
\hline \multirow{2}{*}{ Cow milk } & $\% \mathrm{SNF}=0.25 \mathrm{CLR}+0.25 \mathrm{Fat}+0.39$ & $\% \mathrm{SNF}=0.25 \mathrm{CLR}+0.25 \mathrm{Fat}+0.56$ \\
\cline { 2 - 3 } & $\% \mathrm{TS}=0.25 \mathrm{CLR}+1.25 \mathrm{Fat}+0.39$ & \% $\mathrm{TS}=0.25 \mathrm{CLR}+1.25 \mathrm{Fat}+0.56 \mathrm{a}$ \\
\hline
\end{tabular}

Fig.1 Graphical representation of \% of error in \% SNF of buffalo milk samples (ISI = ISI formula, S1= State1, S2= State $2, \mathrm{~S} 3=$ State 3 formula, N 27 = at $27^{\circ} \mathrm{C}, \mathrm{N} 29=$ at $29^{\circ} \mathrm{C}$ )

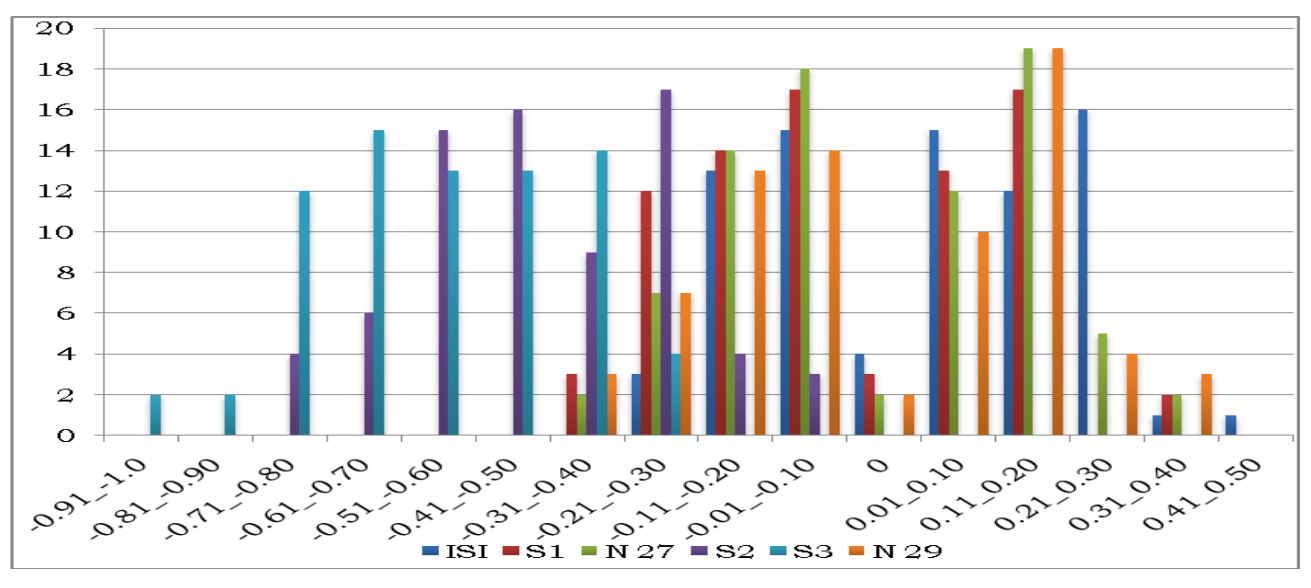


Fig.2 Graphical representation of \% of error in \% SNF of cow milk samples (ISI = ISI formula, $\mathrm{S} 1=$ State $1, \mathrm{~S} 2=$ State $2, \mathrm{~S} 3=$ State 3 formula, N 27 $=$ at $27^{\circ} \mathrm{C}, \mathrm{N} 29=$ at $29^{\circ} \mathrm{C}$ )

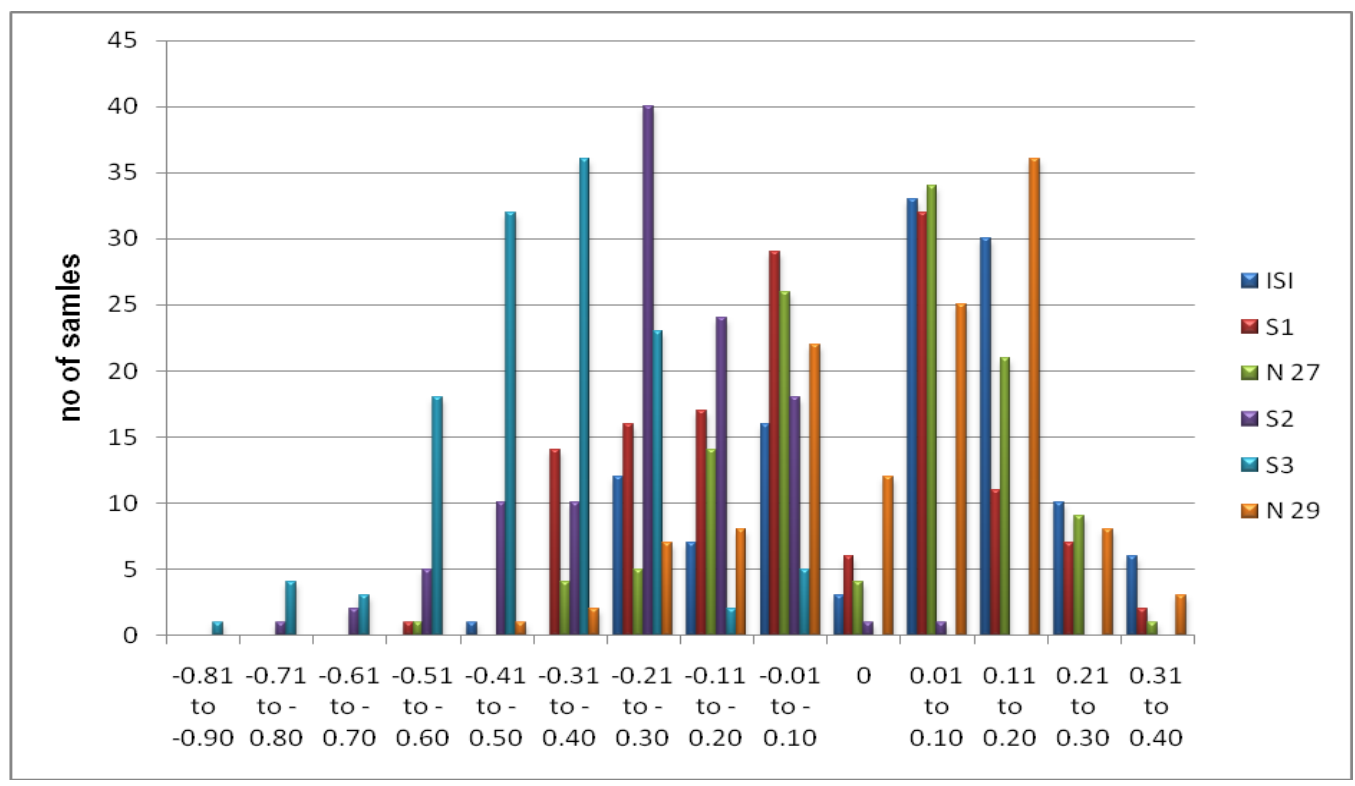

Uniform formulae for SNF and TS in cow and buffalo milk

The SPSS 16.0 version regression equation was used to develop uniform formulae. Three variables (one dependent variable i.e. SNF of gravimetric and two independent variables i.e. Fat and CLR) were investigated. Separately, for each milk (cow and buffalo) two equations were developed one at $27^{\circ} \mathrm{C}$ and another at $29^{\circ} \mathrm{C}$. A regression equation contains one constant value, two coefficients one for fat and one for CLR. If any regression equation is said to be good it should have a good adjusted $\mathrm{R}$ square value. It can be achieved by removal of extreme values which are deviated from average value. A new equation can be seen from table $\mathrm{V}$.

In conclusion the milk, fat and Snf are variable, in India pricing of milk is based on quantity and quality i.e. fat and Snf content of milk and to meet legal standards, in order to get Snf value very near to gravimetric value many things play a role i.e. type of the formula, type of lactometer, temperature of measurement and accuracy of glassware. Existing formulae will underestimate $>0.2 \%$ SNF. Developed formulae in case of cow milk at $27^{\circ} \mathrm{C} 91.52$ and at $29^{\circ} \mathrm{C} 91.93 \%$ samples are in the acceptable range (within $0.2 \%$ error) and in case of buffalo milk at $27^{\circ} \mathrm{C} 80.24$ and at $29^{\circ} \mathrm{C} 77.33 \%$ of samples are in the acceptable range.

\section{References}

Bector, B. S,. and Niraj Sharma.(1980). Estimation of Solids-not-Fat in Milk Using Specific Gravity Lactometers. Indian Dairyman. 33: 249-253.

Indian Standards Institution (IS: 1223, 1970). Specifications for thermometer. New Delhi.

Indian Standards Institution (IS: 1223; part -1, 1970). Specifications for butyrometer and determination of milk fat by Gerber method. New Delhi, (1970).

Indian Standards Institution (IS: 9585, 1980). Specifications for lactometers. New Delhi, ( 1980).

IS:1223, 2001. Apparatus for determination of 
milk fat by Gerber method, (2001) specification. Third revision.

Sandhu, S. S. 2003. Make your Solid-Not-Fat (SNF) calculation easy. Indian Dairyman, 55 (4): 51.

Varricchio, M. L., Di Francia, A., Masucci,
F., Romano, R., \& Proto, V. (2007). Fatty acid composition of Mediterranean buffalo milk fat. Italian Journal of Animal Science, 6(sup1), 509-511.

\section{How to cite this article:}

Arjuna, V. M., N. Laxmana Naik, Akshaykumar, B. K. Ramesh, Shivanand, Sharanabasava and Krishna, K. N. 2020. Development and Validation of Formulae for the Estimation of Solidsnot- Fat and Total Solids Content in Cow and Buffalo Milk. Int.J.Curr.Microbiol.App.Sci. 9(07): 2114-2121. doi: https://doi.org/10.20546/ijcmas.2020.907.246 